\title{
Effects of oral theophylline and oral salbutamol in the treatment of asthma
}

\author{
K P DAWSON AND D M FERGUSSON \\ Department of Paediatrics, Christchurch Clinical School of Medicine, Christchurch Hospital, New Zealand
}

SUMmARY A double-blind randomised controlled trial was conducted to study the effects of oral theophylline alone compared with oral theophylline and salbutamol in a sample of asthmatic children. Each treatment was administered at maximum recommended dosage. Children treated with the theophylline and salbutamol combination had higher pulse rates, lower peak flow measurements, and depressed blood theophylline levels. These results suggest that when given at maximum oral dosage, theophylline and salbutamol in combination, tend to interact negatively producing tachycardia and reduced therapeutic function.

Concern has been expressed about the safety of theophylline and salbutamol when used in combination in the treatment of asthma. This concern has been stimulated by recent and puzzling increases in asthma deaths in New Zealand. ${ }^{1}$ It has been argued that the rise could be due to an increasing use of the combination of long-acting theophylline and salbutamol because of toxic effects of high theophylline dosage on the heart. ${ }^{1}$

To examine the effect of theophylline and salbutamol in combination when compared with theophylline alone, we conducted a randomised trial in which the peak flow rates, blood theophylline levels, and pulse rates of patients treated with theophylline and salbutamol were compared with those of patients receiving theophylline alone.

\section{Method}

The subjects in the trial were 30 asthmatic patients with an age range of 5 to 13 (mean 9.33) years who were regular clinic patients at the Paediatric Department, Christchurch Hospital. Thirteen of them were girls. These patients were randomly assigned on a double-blind basis to one of two treatment regimens:

(1) Salbutamol and theophylline: in this treatment the patient received a combined oral dose of salbutamol and theophylline with dosage being set at $0.1 \mathrm{mg} / \mathrm{kg}$ for salbutamol and $7 \mathrm{mg} / \mathrm{kg}$ for theophylline. These levels were chosen because they are the recommended maximum dosages for children in this age range, and because such dosages appeared to be commonly prescribed.

(2) Theophylline: in this treatment the patients received only oral theophylline, at a dosage of $7 \mathrm{mg} / \mathrm{kg}$.
No patient on short-acting theophylline was given any bronchodilator therapy for a period of 12 hours before the start of the trial. No patient on longacting preparation was given any bronchodilator therapy for 18 hours before the trial.

Comparisons of the two groups with respect to both age and height showed no significant differences: the mean age of the theophylline/salbutamol group was 9.3 years compared with the mean of 9.4 years for the theophylline alone group; mean heights were $132.9 \mathrm{~cm}$ for the theophylline and salbutamol group and $134.3 \mathrm{~cm}$ for the theophylline alone group.

Each subject was studied in hospital for a period of 4 hours during which time the following measurements were taken:

(1) Blood theophylline was measured from blood samples obtained from an indwelling intravenous catheter before administration of the treatment and then at 90, 120, 180, and 240 minutes after treatment. Mean blood theophylline levels before treatment were $8.46 \mu \mathrm{mol} / 1$ for the theophylline group and $7.4 \mu \mathrm{mol} / \mathrm{l}$ for the theophylline and salbutamol group.

(2) Pulse rates were monitored regularly and recorded at $90,120,150,180$, and 240 minutes after the treatment was given.

(3) Peak flow rates were taken with a Wright peak flow meter at 90, 120, 180, and 240 minutes. Peak flow rates were measured as percentage of expected value for the child's age and height.

The trial had ethical approval and in every case was conducted on the basis of informed and written consent by the child's parent. 


\section{Results}

The Figure shows mean pulse rates, peak flow rates (expressed as percentage of expected for age and height), and blood theophylline levels for the theophylline/salbutamol group compared wth the theophylline group. The results show that in terms of pulse rates, peak flow rates, and blood theophylline levels, the mean scores for the two groups had 2 completely non-overlapping distributions with children given the theophylline/salbutamol com-
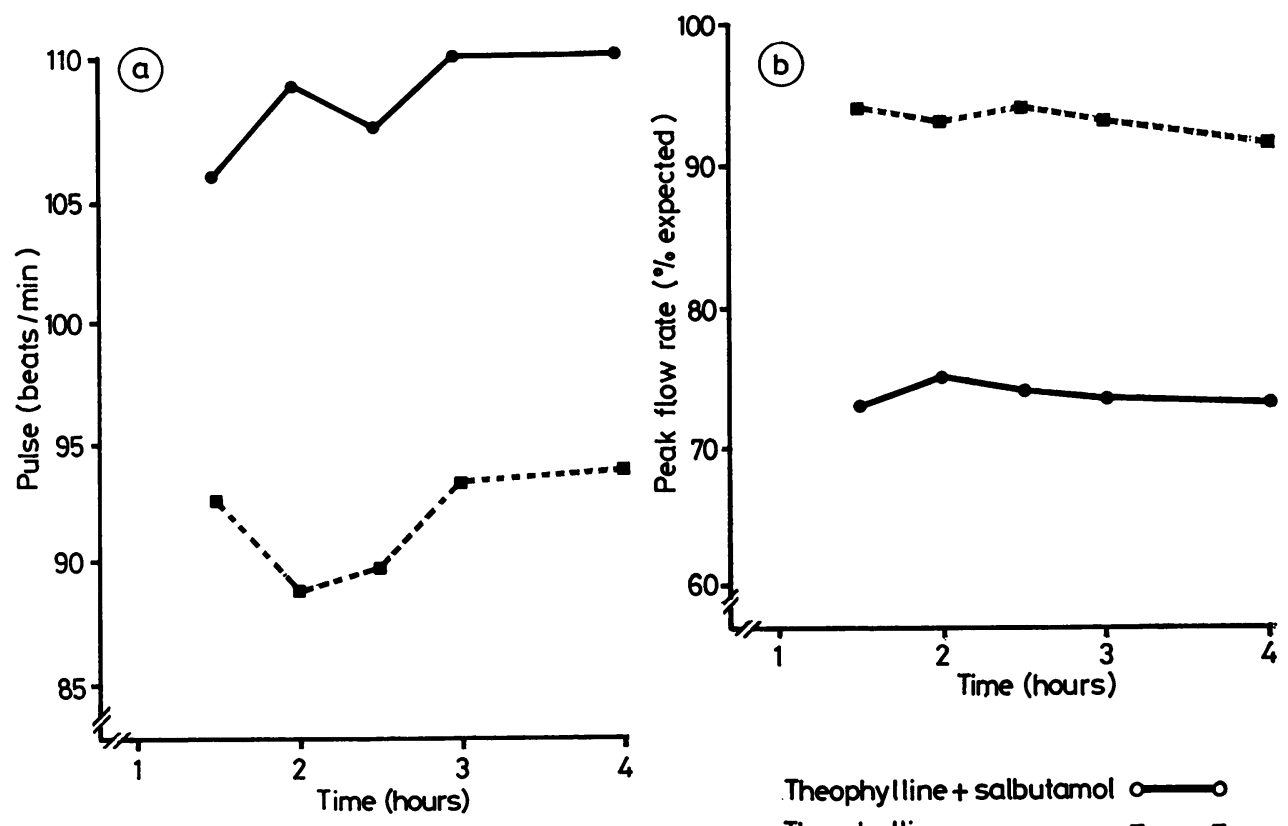

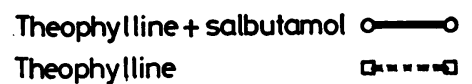

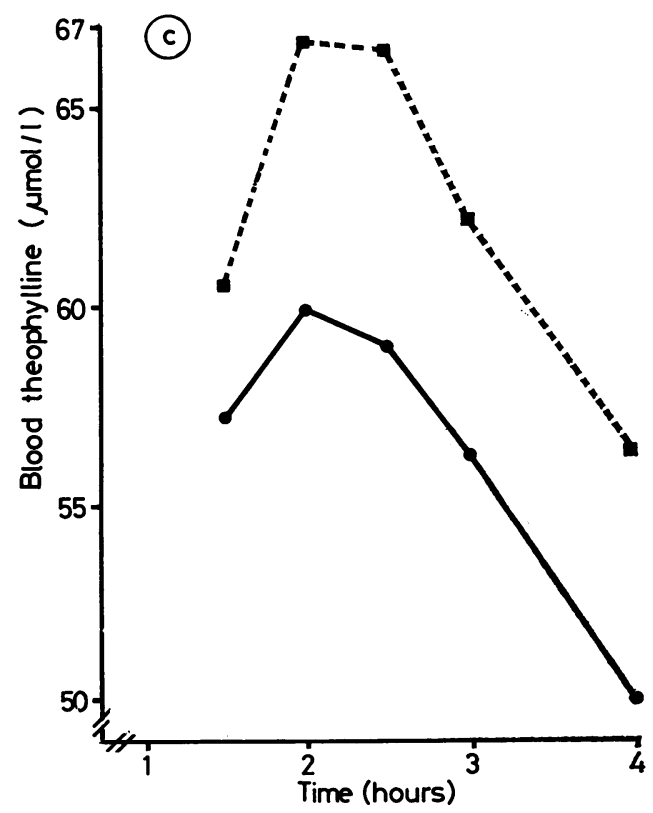

Figure Differences in (a) mean pulse rates, (b) expected peak flow measurements, and (c) blood theophylline levels in the theophylline group compared with the theophylline combined with salbutamol group. 
bination having higher mean pulse rates $(109 \cdot 14$ versus 91.61$)$, lower mean peak flow rates $(70.9 \%$ expected versus $90.9 \%$ expected), and lower mean blood theophylline levels $(56.45$ versus 62.40$)$.

Multivariate analysis of variance of the repeated measures design showed that there was a highly significant $(P<0.001)$ difference between the responses of the two groups on the three parameters during the 4-hour study period. However, univariate analysis of variance showed that the size of the difference tended to vary with each measure: there was a highly significant tendency for the theophylline/salbutamol group to have a higher mean pulse rate $(\mathrm{P}<0.01)$, a significant tendency for the theophylline/salbutamol group to have lower peak flow rates $(P<0.02)$, but the differences in blood theophylline levels failed to reach significance $(0 \cdot 10<P<0.25)$ despite the apparent differences between the two groups. The variation in significance levels between measures, in part, appeared to reflect the small number of subjects studied and differences in the intrinsic variability of the dependent variables.

\section{Discussion}

Salbutamol and theophylline in combination and administered at maximum recommended dosage had different effects from theophylline alone administered at maximum recommended dose.

Children treated with the salbutamol/theophylline combination had increased pulse rates compared with the theophylline group and presumably this reflects the fact that salbutamol is known to produce reflex tachycardia owing to peripheral vasodilatation. ${ }^{2}$ Theophylline however, may have a similar effect by direct cardiac stimulation. ${ }^{3}$ At the same time the therapeutic function of the salbutamol/ theophylline combination, as measured by peak flow rates, was lower than that of theophylline alone. While it was not possible to demonstrate conclusively parallel differences in serum theophylline levels, throughout the trial the salbutamol/theophylline group had consistently lower blood theophylline levels than those treated with theophylline alone. Collectively, these results suggest that at maximum dosage oral salbutamol and oral theophylline tend to interact in a negative way which produces tachycardia, reduced therapeutic effect, and (probably) decreased blood theophylline levels.

These results are inconsistent with the findings of previous studies which have suggested that the salbutamol/theophylline combination is therapeutically as good or better than salbutamol or theophylline alone. ${ }^{4-7}$ This inconsistency may be explained in a number of ways. Previous studies have used lower dosages than reported here ${ }^{56}$ or have calibrated dosage on the basis of serum theophylline levels. ${ }^{47}$ It seems possible that the $\stackrel{\mathcal{O}^{\circ}}{+}$ effects reported here may only occur at higher $\bar{c}$ dosages and that at lower dosage the theophylline/ $\frac{\bar{\sigma}}{\bar{D}}$. salbutamol combination may be more effective. ${ }^{6} \frac{\bar{\sigma}}{\overrightarrow{0}}$ Clearly, studies in which dosage is calibrated on the $\stackrel{\mathbb{Q}}{\Omega}$ basis of blood theophylline may mask the fact that is higher doses of theophylline may be required to $\vec{\circ}$ achieve the same blood theophylline level when theophylline is administered in combination with $\vec{\omega}$ salbutamol. In addition, some studies have examined $\stackrel{\circ}{\circ}$ the short-term effects of inhaled administration, 号 whereas this study has examined the effects of an $\mathrm{G}$ oral preparation during a protracted period. ${ }^{5}$ It seems possible that any or all of these differences in dose levels and methods of administration may $\underset{\perp}{\sim}$ account for the discrepancy between this study and previous research.

These results do not support the view ${ }^{1}$ that recent $\vec{\oplus}$ increases in asthma mortality are the result of $\mathbb{D}$ combinations of theophylline and salbutamol $\underset{\mathbb{D}}{\vec{D}}$ creating toxic blood theophylline levels. However, 쿵 they might suggest that any excess mortality that $\stackrel{\mathbb{D}}{-}$ can be attributed to the theophylline/salbutamol $\vec{\varphi}$ combination (and such an excess has yet to be $\stackrel{\infty}{N}$ demonstrated clearly) might arise because oral doses of theophylline and salbutamol are therapeutically less effective than theophylline alone.

\section{References}

1 Wilson J D, Sutherland D C, Thomas A C. Has the change to beta-agonists combined with oral theophylline increased cases of fatal asthma? Lancet 1981; i: 1235-7.

2 Gibson D G, Coltart D J. Haemodynamic effects of intravenous salbutamol in patients with mitral valve disease: comparison with isoprenaline and atropine. Postgrad Med J 1971 ; 47: Supplement, March, 40-4.

3 Marcus M L, Skelton C L, Grauer L E, Epstein S E. Effects of theophylline on myocardial mechanics. Am J Physiol 1972; 222: 1361-5.

4 Barclay J, Whiting B, Meredith P A, Addis G J. Theophylline-salbutamol interaction, bronchodilator response to salbutamol at maximally effective plasma theophylline concentrations. Br J Clin Pharmacol 1981 ; 11 : 203-8.

5 Pihlajamäki K, Kanto J. Respiratory and circulatory interactions of salbutamol and theophyllamine in asthmatic patients. Int J Clin Pharm Biopharm 1979; 17: 435-8.

6 Groggins R C, Lenney W, Milner A D, Stokes G M. Efficacy of orally administered salbutamol and theophylline in pre-schoolchildren with asthma. Arch Dis Child 1980; 55: 204-6.

7 Lönnerholm G, Foucard T, Londstrom B. Combined treatment with sustained-release theophylline and beta-2adrenoceptor-stimulating agents in chronic childhood asthma. Br Med J 1981; 282: 1029-31.

Correspondence to Dr K P Dawson, Department of Paediatrics, Christchurch Clinical School of Medicine, Christchurch Hospital, Christchurch, New Zealand.

Received 22 April 1982 